\title{
OXYGENATION STRATEGY AND NEUROLOGIC DAMAGE AFTER DEEP HYPOTHERMIC CIRCULATORY ARREST. II. HYPOXIC VERSUS FREE RADICAL INJURY
}

Georg Nollert, $\mathrm{MD}^{\mathrm{a}}$

Mitsugi Nagashima, MD

Jan Bucerius, MD

Toshiharu Shin'oka, MD

Hart G. W. Lidov, MD, $\mathrm{PhD}^{\mathrm{b}}$

Adre du Plessis, $\mathrm{MBChB}, \mathrm{MPH}^{\mathrm{c}}$

Richard A. Jonas, MD
Objectives: Laboratory studies suggest that myocardial reperfusion injury is exacerbated by free radicals when pure oxygen is used during cardiopulmonary bypass. In phase I of this study we demonstrated that normoxic perfusion during cardiopulmonary bypass does not increase the risk of microembolic brain injury so long as a membrane oxygenator with an arterial filter is used. In phase II of this study we studied the hypothesis that normoxic perfusion increases the risk of hypoxic brain injury after deep hypothermia with circulatory arrest. Methods: With membrane oxygenators with arterial filters, 10 piglets $(8-10 \mathrm{~kg})$ underwent 120 minutes of deep hypothermia and circulatory arrest at $15^{\circ} \mathrm{C}$, were rewarmed to $37^{\circ} \mathrm{C}$, and were weaned from bypass. In 5 piglets normoxia $\left(\mathrm{PaO}_{2}\right.$ 64-181 mm Hg) was used during cardiopulmonary bypass and in 5 hyperoxia $\left(\mathrm{PaO}_{2} 400-900 \mathrm{~mm} \mathrm{Hg}\right)$ was used. After 6 hours of reperfusion the brain was fixed for histologic evaluation. Near-infrared spectroscopy was used to monitor cerebral oxyhemoglobin and oxidized cytochrome $a_{,} a_{3}$ concentrations. Results: Histologic examination revealed a significant increase in brain damage in the normoxia group (score 12.4 versus 8.6, $P=.01$ ), especially in the neocortex and hippocampal regions. Cytochrome a, $a_{3}$ and oxyhemoglobin concentrations tended to be lower during deep hypothermia and circulatory arrest in the normoxia group $(P=.16)$. Conclusions: In the setting of prolonged deep hypothermia and circulatory arrest with membrane oxygenators, normoxic cardiopulmonary bypass significantly increases histologically graded brain damage with respect to hyperoxic cardiopulmonary bypass. Near-infrared spectroscopy suggests that the mechanism is hypoxic injury, which presumably overwhelms any injury caused by increased oxygen free radicals. (J Thorac Cardiovasc Surg 1999;117:1172-9)
T he traditional management of cardiopulmonary bypass (CPB) has included the use of high arterial oxygen pressures. In recent years, however, many centers have changed their bypass protocol to normoxic perfusion because of data suggesting increased myocardial injury by free radicals with hyperoxic perfusion. In phase I of this study we demonstrated that normoxic perfusion does not increase the risk of brain injury by gaseous microemboli so long as a membrane oxygenator with

From the Department of Cardiac Surgery, Children's Hospital, and the Department of Surgery, Harvard Medical School, ${ }^{\mathrm{a}}$ and the Departments of Pathology ${ }^{\mathrm{b}}$ and Neurology, ${ }^{\mathrm{c}}$ Children's Hospital and Harvard Medical School, Boston, Mass.

Supported by a Habilitandenstipendium of the Deutsche Forschungsgemeinschaft NO344/1-1 (G.N.). The S-100 enzyme kit was kindly provided by Sangtec Medical AB, Bromma, Sweden. The NIRO 500 system was provided by Hamamatsu Photonics KK, Hamamatsu City, Japan. arterial line filter is employed. In phase II of the study we examine the hypothesis that hypoxic brain injury is increased if normoxic perfusion is employed in the setting of CPB, deep hypothermia, and circulatory arrest.

\section{Methods}

Experimental preparation. Experimental preparation was identical to that in phase I of the study (see page 1166) except that arterial cannulation was through the femoral artery with

Received for publication Aug 28, 1998; revisions requested Oct 30, 1998; revisions received Feb 2, 1999; accepted for publication Feb 19, 1999.

Address for reprints: Richard A. Jonas, MD, Department of Cardiac Surgery, Children's Hospital, 300 Longwood Ave, Boston, MA 02115 .

Copyright (C) 1999 by Mosby, Inc.

$0022-5223 / 99 \$ 8.00+0 \quad \mathbf{1 2 / 1 / 9 8 0 7 3}$ 
an 8F cannula (Medtronic BioMedicus, Inc, Minneapolis, Minn) and a 24F venous cannula (USCI Division, C.R. Bard Inc, Billerica, Mass) was inserted in the right atrium, working through an incision in the third intercostal space.

All animals received humane care in compliance with the "Principles of Laboratory Animal Care" formulated for the National Society for Medical Research and the "Guide for the Care and the Use of Laboratory Animals" prepared by the National Institute of Laboratory Animal Resources and published by the National Institutes of Health (NIH Publication No. 86-23, revised 1985).

CPB technique. In all animals the CPB circuit consisted of a roller pump (Cardiovascular Instrument Corp, Wakefield, Mass), membrane oxygenator (VPCML plus; COBE Cardiovascular, Inc, Arvada, Colo), and sterile tubing (OLSON Medical Sales Inc, Ashland, Mass) with 40- $\mu \mathrm{m}$ arterial filter (pediatric extracorporeal blood filter; Pall Biomedical, Inc, Fajardo, PR). Pump prime and flow rates and alpha-stat strategy were as for phase I. After 30 minutes of cooling all animals underwent 120 minutes of deep hypothermia and circulatory arrest after which $0.25 \mathrm{mg} / \mathrm{kg}$ furosemide, $0.5 \mathrm{~g} / \mathrm{kg}$ mannitol, and $10 \mathrm{~mL}$ sodium bicarbonate were administered into the pump. The animal was then rewarmed to a temperature of $37^{\circ} \mathrm{C}$ during 40 minutes. The heart was defibrillated as necessary at $25^{\circ} \mathrm{C}$. Fresh whole blood from a donor animal was transfused into the pump as required to increase the hematocrit to a range of $20 \%$ to $25 \%$ during rewarming. Ventilation was restarted 10 minutes before the weaning from $\mathrm{CPB}$, with an inspired oxygen fraction of 0.4 (normoxia group) or 1.0 (hyperoxia group). The animal was then weaned from CPB. Intravenous protamine (6 $\mathrm{mg} / \mathrm{kg}$ ) was administered, followed by decannulation once the animal's hemodynamic condition was stable. If deemed necessary, dopamine was administered intravenously to facilitate weaning. After the operation all animals remained fully sedated, paralyzed, and intubated and were monitored continuously for 6 hours from the start of reperfusion after CPB, at which time the chest was opened by median sternotomy to allow perfusion fixation of the brain.

\section{Data collection}

Near-infrared spectroscopy. Before the operation a pair of fiberoptic optodes for near-infrared spectroscopy (NIRS) was attached to the head of the animal. The optode spacing was 3.0 to $3.5 \mathrm{~cm}$ in a coronal plane. The 2 optodes, a transmitter and a receiver of laser light at near-infrared wavelengths, were connected to a near-infrared spectrometer (NIRO-500; Hamamatsu Photonics KK, Hamamatsu City, Japan), which calculated relative concentration changes in oxyhemoglobin, deoxygenated hemoglobin, and oxidized cytochrome $\mathrm{a}_{3} \mathrm{a}_{3}$ in brain tissue. Data were recorded every 10 seconds throughout the experiment. A steep and sudden decrease of oxyhemoglobin, hemoglobin, and cytochrome a, $\mathrm{a}_{3}$ concentrations after the start of brain perfusion validated the accurate placement of the optodes in all experiments. A differential path length factor of 3.85 was assumed for the calculation of absolute chromophore changes. ${ }^{1}$

Blood gases and biochemical analyses. Arterial and venous (jugular bulb) blood gas values, including electrolyte, glucose, and lactate concentrations, were measured at baseline, 5 minutes after the start of $\mathrm{CPB}$, every 10 minutes during $\mathrm{CPB}, 30$ minutes after the end of $\mathrm{CPB}$, and at the end of the experiment (Nova 900; Nova Biomedical, Waltham, Mass). Additional blood samples were taken at baseline, 30 minutes after termination of $\mathrm{CPB}$, and at the end of the experiment to determine concentrations of products of lipid peroxidation and nitric oxide production. Concentrations of enzyme markers of ischemic brain damage, neuron-specific enolase and S100 , were assessed at baseline and at the end of the experiment. The blood samples were immediately centrifuged and the serum was stored at $-80^{\circ} \mathrm{C}$ for further processing. Glutamic oxaloacetate transaminase, glutamic pyruvic transaminase, lactate dehydrogenase, and creatine kinase were measured at the end of the experiment by standard laboratory kits and compared among groups.

Products of lipid peroxidation (malonaldehyde and 4hydroxy-2[E]-nonenal;) were measured with a specific colorimetric assay kit (Lipid Peroxidation Kit; CN Biosciences, Inc, San Diego, Calif). Absorbance at $586 \mathrm{~nm}$ was determined with a standard spectrophotometer. Interference of heparin with the results was ruled out by control measurements. ${ }^{2}$

As a measure of nitric oxide production, concentrations of the nitric oxide metabolites nitrite and nitrate were determined. The blood samples were centrifuged for 3 hours at $2000 \mathrm{rpm}$ with a 10- $\mu \mathrm{m}$ filter (Centricon 10; Amicon Inc, Beverly, Mass). Nitrate was transformed to nitrite by 3 hours of incubation with nitrate reductase (Cayman's Nitrate/Nitrite Assay Kit; Alexis Corporation, San Diego, Calif). After the addition of Griess reagent, absorbance at $550 \mathrm{~nm}$ was measured with a standard 96-well plate reader. ${ }^{3}$

Concentration of S-100 was measured by a luminescence immunoassay (Sangtec 100; Sangtec Medical AB, Bromma, Sweden), which determines the S100 B-subunit specific for brain damage at a detection limit of $0.02 \mathrm{mg} / \mathrm{L}$. The emitted light was detected by a luminometer (Lumat LB 9501; Berthold Systems, Inc, Aliquippa, Pa). ${ }^{4}$

Neuron-specific enolase was assayed by an enzyme immunoassay (Cobas Core NSE EIA; Roche Diagnostics Division, Basel, Switzerland) specific for the $\gamma$ subunit. $^{5}$

Histologic evaluations. The brain of the animal was fixed by perfusion with $4 \%$ paraformaldehyde 6 hours after reperfusion. Through a median sternotomy, a $12 \mathrm{~F}$ cannula was introduced into the brachiocephalic trunk and $1 \mathrm{~L}$ of a balanced electrolyte solution (Normosol; Abbott Laboratories, Abbott Park, Ill) was infused through the cannula from a height of $1.5 \mathrm{~m}$, followed by $4 \mathrm{~L}$ of $4 \%$ paraformaldehyde. The superior vena cava was opened to vent the effluent. The animal was then decapitated and the head was submerged in $10 \%$ formalin for an additional 24 hours, after which the brain was removed and submerged in $4 \%$ formaldehyde, typically for 2 weeks.

After fixation the brain was blocked into 8 to 10 coronal slabs that were embedded in paraffin, and $7-\mu \mathrm{m}$ sections were stained with hematoxylin and eosin. Injury to the brain was 
Table I. Experimental conditions

\begin{tabular}{|c|c|c|c|c|c|c|}
\hline \multirow[b]{2}{*}{ Parameter } & \multirow[b]{2}{*}{ Sample } & \multirow[b]{2}{*}{ Group } & \multirow[b]{2}{*}{ Baseline } & \multicolumn{3}{|c|}{ Cooling } \\
\hline & & & & $5 \min$ & $15 \mathrm{~min}$ & $25 \min$ \\
\hline \multirow{4}{*}{$\mathrm{Po}_{2}(\mathrm{~mm} \mathrm{Hg})$} & Arterial & Normoxia & $130 \pm 12 *$ & $100 \pm 7 *$ & $135 \pm 40^{*}$ & $178 \pm 25^{*}$ \\
\hline & Arterial & Hyperoxia & $534 \pm 42 *$ & $767 \pm 44^{*}$ & $870 \pm 30 *$ & $900 \pm 0 *$ \\
\hline & Bulbus jugularis & Normoxia & $57 \pm 9 \dagger$ & $38 \pm 2 \dagger$ & $46 \pm 8 \dagger$ & $57 \pm 10 \dagger$ \\
\hline & Bulbus jugularis & Hyperoxia & $57 \pm 5 \dagger$ & $56 \pm 3 \dagger$ & $83 \pm 6 \dagger$ & $153 \pm 27 \dagger$ \\
\hline \multirow{2}{*}{$\mathrm{PCO}_{2}(\mathrm{~mm} \mathrm{Hg})$} & Arterial & Normoxia & $37.4 \pm 2.3$ & $34.3 \pm 2.7$ & $40.5 \pm 3.5$ & $37.8 \pm 4.2$ \\
\hline & Arterial & Hyperoxia & $31.8 \pm 2.3$ & $33.0 \pm 4.2$ & $37.4 \pm 4.3$ & $37.1 \pm 5.0$ \\
\hline \multirow[t]{2}{*}{$\mathrm{pH}$} & Arterial & Normoxia & $7.52 \pm 0.02$ & $7.55 \pm 0.03$ & $7.46 \pm 0.02$ & $7.46 \pm 0.02$ \\
\hline & Arterial & Hyperoxia & $7.57 \pm 0.02$ & $7.56 \pm 0.03$ & $7.52 \pm 0.04$ & $7.52 \pm 0.03$ \\
\hline \multirow[t]{2}{*}{ Hematocrit (\%) } & Arterial & Normoxia & $28 \pm 2$ & $21 \pm 1$ & $24 \pm 1$ & $24 \pm 1$ \\
\hline & Arterial & Hyperoxia & $28 \pm 1$ & $22 \pm 1$ & $23 \pm 1$ & $23 \pm 1$ \\
\hline Glucose (mg/dL) & Arterial & Normoxia & $129 \pm 25$ & $109 \pm 16$ & $113 \pm 17$ & $144 \pm 37$ \\
\hline \multirow{2}{*}{$\begin{array}{l}\text { Glucose uptake } \\
\text { (mg/dL) }\end{array}$} & Arterial and bulbus jugularis & Normoxia & $7 \pm 7$ & $22 \pm 16$ & $4 \pm 2$ & $24 \pm 11$ \\
\hline & Arterial and bulbus jugularis & Hyperoxia & $5 \pm 1$ & $12 \pm 9$ & $4 \pm 3$ & $2 \pm 2$ \\
\hline \multirow[t]{2}{*}{ Lactate (mg/dL) } & Arterial & Normoxia & $2.3 \pm 0.4$ & $3.2 \pm 0.5$ & $4.5 \pm 0.5$ & $4.7 \pm 0.4$ \\
\hline & Arterial & Hyperoxia & $4.0 \pm 0.7$ & $3.5 \pm 0.4$ & $4.4 \pm 0.6$ & $4.7 \pm 0.6$ \\
\hline \multirow{2}{*}{$\begin{array}{l}\text { Lactate increase } \\
\qquad(\%)\end{array}$} & Bulbus jugularis & Normoxia & & $56 \pm 44$ & $72 \pm 56$ & $82 \pm 56$ \\
\hline & Bulbus jugularis & Hyperoxia & & $5 \pm 16$ & $13 \pm 15$ & $16 \pm 15$ \\
\hline \multirow{2}{*}{\multicolumn{2}{|c|}{$\begin{array}{l}\text { Esophageal } \\
\text { temperature }\left({ }^{\circ} \mathrm{C}\right)\end{array}$}} & Normoxia & $36.7 \pm 0.6$ & $26.8 \pm 1.3$ & $16.9 \pm 1.5$ & $13.7 \pm 0.4$ \\
\hline & & Hyperoxia & $37.5 \pm 0.3$ & $28.8 \pm 1.0$ & $20.1 \pm 1.0$ & $15.3 \pm 0.6$ \\
\hline \multirow{2}{*}{$\begin{array}{l}\text { Mean arterial pressure } \\
\quad(\mathrm{mm} \mathrm{Hg})\end{array}$} & & Normoxia & $107 \pm 11$ & $84 \pm 12$ & $80 \pm 7$ & $81 \pm 8$ \\
\hline & & Hyperoxia & $78 \pm 5$ & $76 \pm 13$ & $86 \pm 9$ & $83 \pm 6$ \\
\hline
\end{tabular}

Blood gas values are not corrected for temperature. Differences between groups were calculated by means of repeated measures for a specific phase: baseline, cooling, deep hypothermia and circulatory arrest, rewarming, and after bypass.

$* P<.01$ between groups.

$\dagger P<.05$ between groups.

histologically evaluated by a pathologist in a blinded fashion. Items on a standardized list of 24 of the major gray and white matter structures according to the nomenclature for porcine neuroanatomy, as previously described by Yoshikawa, ${ }^{6}$ were examined; several of the most consistently damaged areas were grouped and scored cumulatively as 4 categories: the neocortex, the hippocampus, the caudate nucleus, and the cerebellum. As in previous studies, ${ }^{7}$ neuropathologic damage was evaluated primarily by the presence of hypereosinophilic shrunken neurons with karyorrhectic nuclei suggestive of recent hypoxic-ischemic injury. Histologic changes were rated on an arbitrary scale: 0 , represented no damage, 1 represented isolated damaged neurons, 2 , represented small clusters of damaged neurons, 3 represented large clusters of injured neurons, 4 represented completely damaged neurons, and 5 represented frank cavitated lesions with necrosis.

Statistical analysis. All results were expressed as mean \pm SEM. The operation was divided into 5 phases: baseline, cooling, deep hypothermia and circulatory arrest, rewarming, and reperfusion. To calculate differences between groups within a phase the repeated measures function was used. The Mann-Whitney $U$ test was used for the analysis of the histologic score. Statistical analyses were facilitated by SPSS statistical software (version 7.0 for Windows; SPSS Inc, Chicago, Ill).

\section{Results}

Table I summarizes the experimental conditions of the 2 groups. Animals were similar in size and there were no differences except for $\mathrm{PO}_{2}$ between the experimental conditions before and during the operation. $\mathrm{PaO}_{2}$ and $\mathrm{PO}_{2}$ in the jugular bulb decreased during rewarming and showed lowest values at the end of rewarming. Lactate levels in the jugular bulb increased significantly more from baseline values during rewarming and reperfusion in the normoxia group (480\% versus $170 \%$ at the end of rewarming, $P<.05)$. Glucose levels tended to be higher in the normoxia group during rewarming $(P=.051)$ and the arterial-jugular venous glucose difference was significantly higher $(P=.028)$ during this phase in the normoxia group. In the normoxia group 2 animals needed dopamine infusion for weaning from bypass, whereas no animals from the hyperoxia group required dopamine.

Near-infrared spectroscopic measurements. There were no statistically significant differences between the groups with respect to the cytochrome $a, a_{3}$ or oxyhemoglobin levels in any phase of the procedure (Fig 1). However, both parameters tended to be lower in the 


\begin{tabular}{|c|c|c|c|c|c|c|c|}
\hline \multicolumn{2}{|c|}{$\begin{array}{l}\text { Deep hypothermia } \\
\text { and circulatory arrest }\end{array}$} & \multicolumn{4}{|c|}{ Rewarming } & \multicolumn{2}{|c|}{ Off bypass } \\
\hline \multirow[t]{19}{*}{$60 \mathrm{~min}$} & $120 \mathrm{~min}$ & $5 \min$ & $15 \mathrm{~min}$ & $25 \mathrm{~min}$ & $35 \mathrm{~min}$ & $30 \mathrm{~min}$ & End \\
\hline & & $90 \pm 7 *$ & $90 \pm 11^{*}$ & $64 \pm 5^{*}$ & $75 \pm 10^{*}$ & $181 \pm 57$ & $172 \pm 37$ \\
\hline & & $646 \pm 37 *$ & $600 \pm 47^{*}$ & $545 \pm 42 *$ & $519 \pm 22 *$ & $236 \pm 110$ & $408 \pm 87$ \\
\hline & & $60 \pm 5 \dagger$ & $47 \pm 6 \dagger$ & $47 \pm 8 \dagger$ & $32 \pm 2 \dagger$ & $50 \pm 8$ & $48 \pm 11$ \\
\hline & & $113 \pm 15 \dagger$ & $62 \pm 9 \dagger$ & $56 \pm 10 \dagger$ & $65 \pm 9 \dagger$ & $69 \pm 20$ & $49 \pm 6$ \\
\hline & & $50.8 \pm 4.5$ & $33.2 \pm 6.1$ & $29.6 \pm 5.2$ & $24.4 \pm 5.6$ & $45.0 \pm 6.3$ & $39.5 \pm 2.2$ \\
\hline & & $50.8 \pm 4.2$ & $30.0 \pm 6.2$ & $31.7 \pm 6.1$ & $30.3 \pm 4.5$ & $41.0 \pm 2.9$ & $40.7 \pm 2.4$ \\
\hline & & $7.33 \pm 0.04$ & $7.45 \pm 0.06$ & $7.45 \pm 0.03$ & $7.47 \pm 0.04$ & $7.31 \pm 0.03$ & $7.46 \pm 0.06$ \\
\hline & & $7.39 \pm 0.03$ & $7.49 \pm 0.04$ & $7.47 \pm 0.04$ & $7.50 \pm 0.04$ & $7.34 \pm 0.05$ & $7.51 \pm 0.03$ \\
\hline & & $22 \pm 1$ & $25 \pm 1$ & $26 \pm 1$ & $26 \pm 1$ & $32 \pm 1$ & $26 \pm 4$ \\
\hline & & $20 \pm 1$ & $22 \pm 1$ & $24 \pm 1$ & $26 \pm 1$ & $30 \pm 2$ & $32 \pm 3$ \\
\hline & & $208 \pm 22$ & $269 \pm 27$ & $260 \pm 43$ & $261 \pm 46$ & $219 \pm 53$ & $125 \pm 27$ \\
\hline & & $132 \pm 16$ & $168 \pm 36$ & $159 \pm 33$ & $150 \pm 29$ & $126 \pm 28$ & $102 \pm 10$ \\
\hline & & $58 \pm 11 \dagger$ & $59 \pm 11 \dagger$ & $41 \pm 10 \dagger$ & $31 \pm 7 \dagger$ & $6 \pm 8$ & $6 \pm 4$ \\
\hline & & $17 \pm 5 \dagger$ & $29 \pm 15 \dagger$ & $15 \pm 6 \dagger$ & $12 \pm 2 \dagger$ & $9 \pm 5$ & $13 \pm 4$ \\
\hline & & $10.0 \pm 0.6$ & $11.5 \pm 0.5$ & $11.9 \pm 1.0$ & $12.3 \pm 1.3$ & $12.8 \pm 0.8$ & $7.9 \pm 2.7$ \\
\hline & & $9.8 \pm 1.5$ & $11.3 \pm 1.8$ & $10.4 \pm 0.8$ & $10.6 \pm 0.7$ & $10.0 \pm 0.9$ & $3.4 \pm 0.5$ \\
\hline & & $314 \pm 73 \dagger$ & $429 \pm 95 \dagger$ & $436 \pm 76 \dagger$ & $482 \pm 87 \dagger$ & $478 \pm 73 \dagger$ & $281 \pm 142 \dagger$ \\
\hline & & $142 \pm 41 \dagger$ & $173 \pm 45 \dagger$ & $156 \pm 35 \dagger$ & $170 \pm 42 \dagger$ & $149 \pm 27 \dagger$ & $0 \pm 18 \dagger$ \\
\hline $18.3 \pm 0.2$ & $18.6 \pm 0.2$ & $25.7 \pm 0.5$ & $33.7 \pm 0.8$ & $37.1 \pm 0.7$ & $38.4 \pm 0.3$ & $34.7 \pm 0.5$ & $37.0 \pm 0.5$ \\
\hline $17.9 \pm 0.5$ & $18.3 \pm 0.4$ & $23.7 \pm 1.4$ & $31.1 \pm 0.8$ & $35.7 \pm 0.9$ & $37.4 \pm 0.6$ & $35.2 \pm 0.4$ & $37.5 \pm 0.7$ \\
\hline & & $69 \pm 5$ & $73 \pm 9.0$ & $85 \pm 10.5$ & $94 \pm 11.4$ & $77 \pm 7$ & $98 \pm 11$ \\
\hline & & $58 \pm 5$ & $92 \pm 12.4$ & $94 \pm 4.0$ & $95 \pm 5.3$ & $83 \pm 5$ & $114 \pm 6$ \\
\hline
\end{tabular}

normoxia group during deep hypothermia and circulatory arrest $(P=.16)$.

Biochemical results. Biochemical results are shown in Table II. The S-100 level was increased at the end of the experiment with respect to baseline values $(P=$ .033) and tended to be slightly higher in the normoxia group (1.52 versus $0.76 \mu \mathrm{g} / \mathrm{L}, P=.352)$. A tendency towards higher values in the normoxia group was also seen for neuron-specific enolase (6.14 versus 1.74 $\mu \mathrm{g} / \mathrm{L}, P=.463)$. Nitric oxide production measured by the nitrite and nitrate concentrations in arterial and brain venous blood declined from baseline to the end of the experiment $(P<.05)$ without any significant differences between groups. Concentrations of products of lipid peroxidation (malonaldehyde and 4-hydroxy$2[\mathrm{E}]$-nonenal) were significantly increased from baseline values after CPB and 6 hours of reperfusion in both groups $(55 \%$ and $36 \%$, respectively, $P<.05)$. Concentrations of the lipid peroxidation products in the jugular bulb tended to be higher in the hyperoxia group at the end of the experiment $(P=.14)$. Glutamic oxaloacetate transaminase, glutamic pyruvic transaminase, creatine kinase, and lactate dehydrogenase con- centrations did not show any differences between groups.

Neuropathologic results. Neuropathologic results are shown in Fig 2. Neurons with the typical histopathologic features of hypoxic-ischemic injury, as found in previous studies, were identifiable. Injury occurred primarily in the frontoparietal cerebral cortex and to a lesser extent in the caudate nucleus, in the distribution described previously. ${ }^{7}$ In addition, neurons exhibiting such features of damage were found in the dentate gyrus of the hippocampal pyramidal layer. There was a further lesion that had not been seen in our group's previous studies, a vacuolation of the Purkinje cells and molecular layer of the cerebellar cortex. These neurons did not exhibit eosinophilic cytoplasm, and although the vacuolation made observation of the perikaryon unreliable the nuclei did not appear pyknotic or karyorrhectic. Presumably the vacuolation in the molecular layer reflected expansion or swelling of the apical dendrites of the Purkinje cells.

There was a significant increase in brain damage in the normoxia group with respect to that in the hyperoxia group (score 12.4 versus $8.6 ; P=.01$ ), especially in the neocortex and hippocampal regions. 

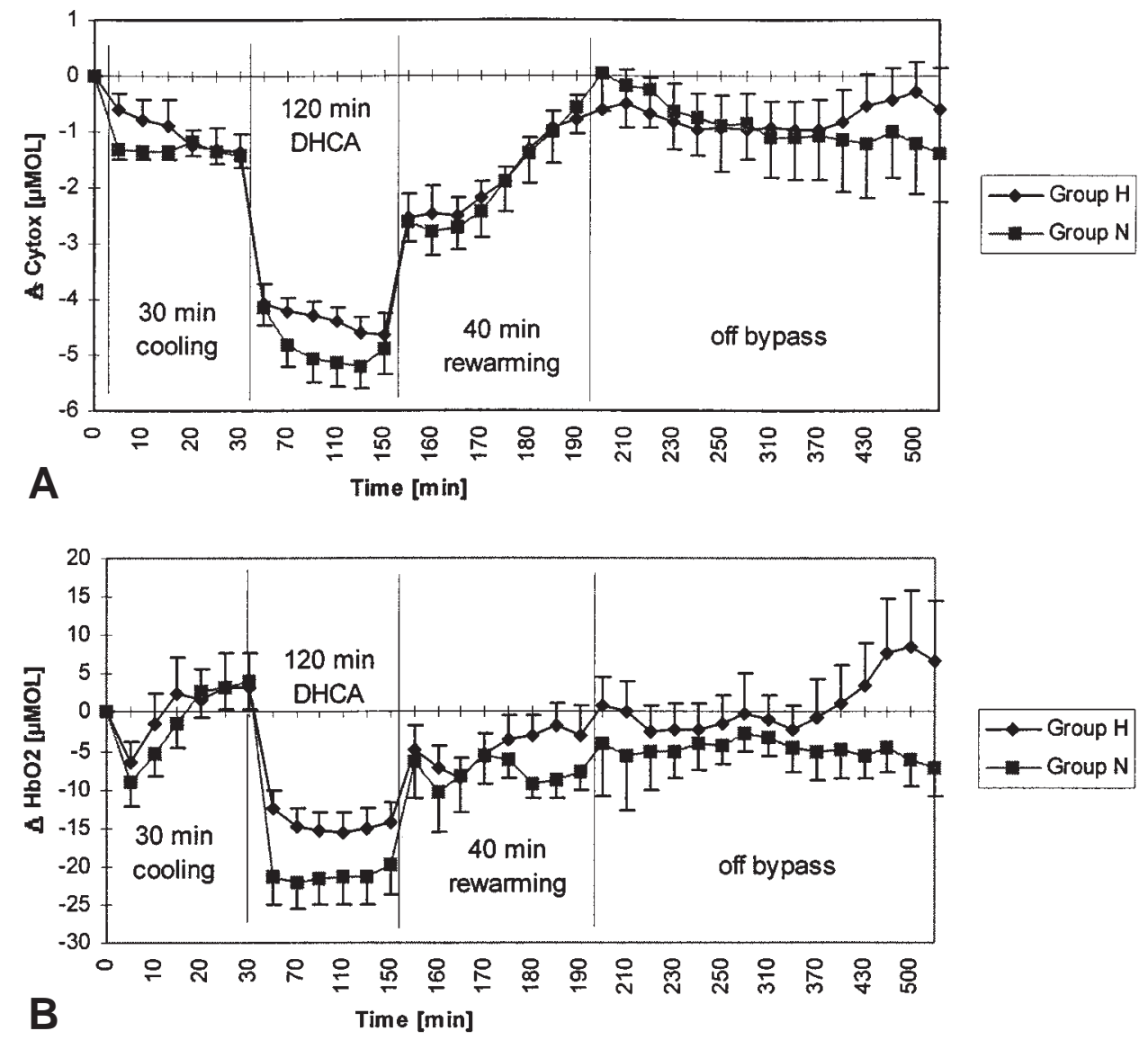

Fig 1. Time course of cytochrome $\mathrm{a}_{3} \mathrm{a}_{3}$ and oxyhemoglobin concentrations during operation in hyperoxia group (group $H$ ) and normoxia group (group $N$ ). A, Cytochrome a, $\mathrm{a}_{3}($ Cytox) levels decreased during cooling and dropped steeply with onset of deep hypothermia and circulatory arrest (DHCA). Cytochrome a, $\mathrm{a}_{3}$ values decreased slightly further during deep hypothermia and circulatory arrest and increased again with rewarming, reaching baseline values at end of CPB. B, Initial drop in oxyhemoglobin ( $\mathrm{HbO2}$ ) concentration with hemodilution at the start of CPB was followed by an increase above baseline values during further cooling. Deoxygenation took place immediately after onset of deep hypothermia and circulatory arrest, plateauing within 20 minutes. Oxyhemoglobin concentration recovered with beginning of rewarming, but values in normoxia group did not reach baseline during 6 hours of reperfusion. Cytochrome $\mathrm{a}_{,} \mathrm{a}_{3}$ and oxyhemoglobin values tended to be lower in normoxia group than in hyperoxic group during deep hypothermia and circulatory arrest $(P=.16)$.

\section{Discussion}

Normoxic management of CPB resulted in greater cerebral injury in piglets undergoing 120 minutes of deep hypothermia and circulatory arrest than did hyperoxic management of CPB. The difference in injury, as determined by histologic examination, achieved statistical significance. Biochemical markers of cerebral injury showed a consistent trend toward greater injury in the normoxia group. Phase I of this study suggested that the mechanism of this injury is not likely to be gaseous microemboli. The trends observed in NIRS suggest that the mechanism may be hypoxia, as suggested by the redox state of cytochrome $\mathrm{a}_{3} \mathrm{a}_{3}$, particularly during the period of extended circulatory arrest.

Ihnken and associates ${ }^{8}$ have emphasized the important role of oxygen free radicals in exacerbating myocardial injury during reperfusion after ischemia. They reported higher lipid oxygenation, increased nitric oxide formation, and worse cardiac contractility with hyperoxic management of CPB after hypoxia and ischemia-reperfusion of immature canine hearts than with normoxic management. ${ }^{8}$ Furthermore, recent clinical studies comparing hyperoxic and normoxic man- 


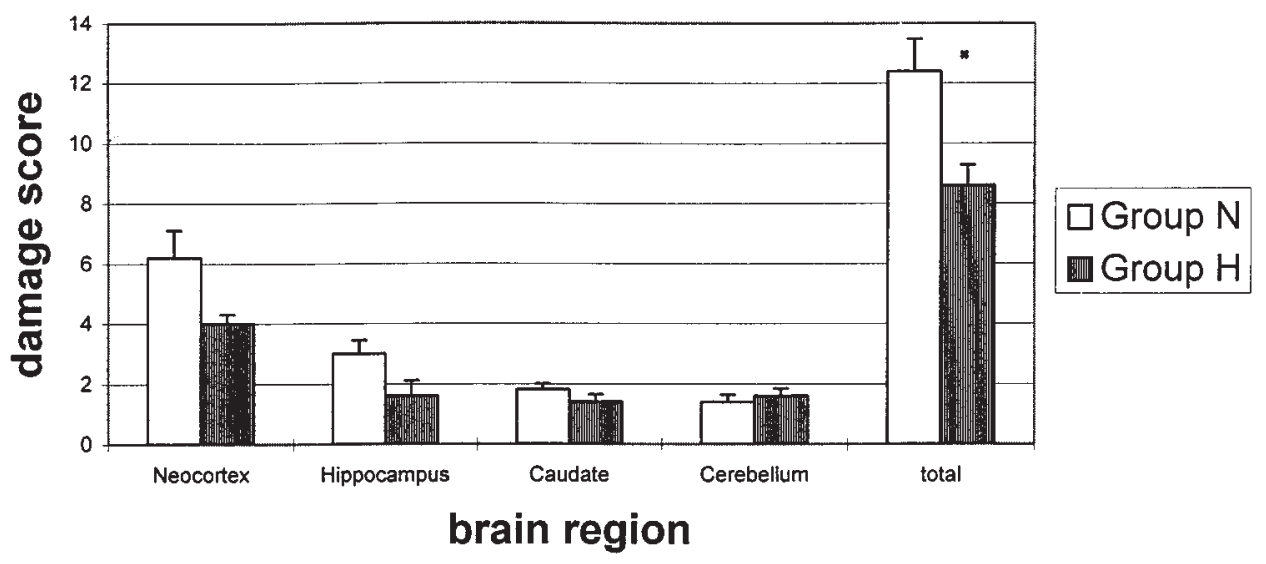

Fig 2. Histopathologic damage in hyperoxia group (group $H$ ) and normoxia group ( group $N$ ). After perfusion and fixation of brain 6 hours after start of reperfusion, distinct regions of brains were analyzed by light microscopy with a scoring system ranging from 0 to 5 (see Methods section). Damage scores for all regions were summed and shown as single values for anatomic structures neocortex, hippocampus, caudate nucleus, and cerebellum and for total brain (eg, score of neocortex was assessed by adding scores of the 4 cortex regions, frontal, temporal, occipital, and parietal). Most severe damage was seen in the neocortex and hippocampal regions. Normoxic management of CPB led to a highly significant increase in brain damage with respect to hyperoxic management of CPB. Asterisk represents $P=.01$.

agement of $\mathrm{CPB}$ in cyanotic children also revealed higher damage from oxygen free radicals, as assessed by products of lipid peroxidation, after reperfusion. ${ }^{9,10}$ These data have led many pediatric cardiac surgery centers to change from hyperoxic to normoxic management of CPB.

Increased lipid peroxidation, a marker of free oxygen radical damage, was indeed observed in our study, with higher oxygenation during $\mathrm{CPB}$ tending to increase these products as would be anticipated. However, oxygen free radicals are only one of several possible causes of neurologic damage, and their detrimental effects in the hyperoxia group were outweighed by other factors.

In keeping with other studies, ${ }^{11}$ nitric oxide production decreased until the animals were killed 6 hours after deep hypothermia and circulatory arrest in this study. However, there were no differences between groups. A decrease in nitric oxide could play a role in the pathogenesis of brain injury by causing impairment of cerebral perfusion and metabolism, ${ }^{12}$ but our results indicate that the observed differences in brain injury are unlikely to be due to differences in nitric oxide metabolism.

Different areas of the brain are known to have different degrees of vulnerability to a global hypoxicischemic insult such as is imposed during deep hypothermia and circulatory arrest. In rodent models the hippocampus (responsible for short-term memory) is usually most severely affected. The pattern of histo- logically demonstrated brain injury in this study was slightly different from that previously seen in our longer term survival studies of pigs that were killed on the fourth postoperative day after deep hypothermia and circulatory arrest. ${ }^{13}$ The damage in this study was much more marked in the hippocampus. The differences between studies may be explained by the longer duration of ischemia (100 vs 120 minutes), phagocytosis of the damaged neurons during the longer survival interval, or regional variations in the time course of delayed neuronal injury.

It is interesting that our neuropathologist (who as in our previous studies was blinded to treatment assignment) was able to discern any damage at 6 hours after injury, because the neuropathologic literature suggests that injury is only detectable at the light microscopic level after 8 to 12 hours. Other than a greater degree of injury in the hippocampus, the pattern was for the most part similar to that seen previously after deep hypothermia and circulatory arrest in piglets but much less severe than would be expected after 120 minutes of circulatory arrest. It is probable that animals from both groups would have shown more severe damage had they been allowed to survive for 4 to 5 days because of both maturation of the histologic changes and ongoing delayed neuronal death.

Although we have speculated that the mechanism of improved outcome with hyperoxic perfusion is a simple improvement in intracellular brain oxygenation, 
Table II. Biochemical results

\begin{tabular}{|c|c|c|c|c|c|c|c|}
\hline Parameter & Group & $\begin{array}{c}\text { Site of } \\
\text { measurement }\end{array}$ & Baseline & $\begin{array}{l}30 \text { min } \\
\text { off bypass }\end{array}$ & $\begin{array}{c}\text { Increase } \\
(\%)\end{array}$ & $\begin{array}{c}\text { End of } \\
\text { experiment }\end{array}$ & $\begin{array}{c}\text { Increase } \\
(\%)\end{array}$ \\
\hline \multirow[t]{2}{*}{$\mathrm{S}-100(\mu \mathrm{g} / \mathrm{L})$} & Normoxia & Bulbus jugularis & $0.53 \pm 0.24$ & & & $1.52 \pm 1.75$ & $186^{*}$ \\
\hline & Hyperoxia & Bulbus jugularis & $0.23 \pm 0.26$ & & & $0.76 \pm 0.60$ & $230^{*}$ \\
\hline \multirow{2}{*}{$\begin{array}{l}\text { Neuron-specific enolase } \\
(\mu \mathrm{g} / \mathrm{L})\end{array}$} & Normoxia & Bulbus jugularis & $4.24 \pm 3.89$ & & & $6.14 \pm 3.58$ & 45 \\
\hline & Hyperoxia & Bulbus jugularis & $2.34 \pm 5.36$ & & & $1.74 \pm 6.1$ & -25 \\
\hline \multirow[t]{4}{*}{ Nitrite and nitrate $(\mu \mathrm{mol} / \mathrm{L})$} & Normoxia & Arterial & $68 \pm 18.1$ & $53 \pm 6.8$ & $-22^{*}$ & $41 \pm 15.0$ & $-40 *$ \\
\hline & Hyperoxia & Arterial & $90 \pm 25.4$ & $76 \pm 18.8$ & $-16^{*}$ & $62 \pm 23.6$ & $-31 *$ \\
\hline & Normoxia & Bulbus jugularis & $63 \pm 13.6$ & $49 \pm 12.9$ & $-20^{*}$ & $45 \pm 15.6$ & $-29^{*}$ \\
\hline & Hyperoxia & Bulbus jugularis & $97 \pm 22.1$ & $79 \pm 14.9$ & $-19^{*}$ & $69 \pm 18.4$ & $-29 *$ \\
\hline \multirow{4}{*}{$\begin{array}{l}\text { Ratio of malonaldehyde } \\
\text { to 4-hydroxy-2(E)-nonenal }\end{array}$} & Normoxia & Arterial & $1.7 \pm 0.21$ & $2.7 \pm 0.30$ & $59^{*}$ & $2.1 \pm 0.32$ & $24^{*}$ \\
\hline & Hyperoxia & Arterial & $2.1 \pm 0.37$ & $3.0 \pm 0.42$ & $43^{*}$ & $3.2 \pm 0.85$ & $52^{*}$ \\
\hline & Normoxia & Bulbus jugularis & $2.1 \pm 0.09$ & $3.2 \pm 0.22$ & $51^{*}$ & $2.4 \pm 0.16$ & $14^{*}$ \\
\hline & Hyperoxia & Bulbus jugularis & $2.2 \pm 0.24$ & $3.4 \pm 0.23$ & $55^{*}$ & $3.6 \pm 0.66$ & $64^{*}$ \\
\hline \multirow[t]{2}{*}{ Creatinine kinase (U/L) } & Normoxia & Arterial & & & & $3346 \pm 822$ & \\
\hline & Hyperoxia & Arterial & & & & $3932 \pm 473$ & \\
\hline \multirow{2}{*}{$\begin{array}{l}\text { Lactate dehydrogenase } \\
\text { (U/L) }\end{array}$} & Normoxia & Arterial & & & & $2052 \pm 702$ & \\
\hline & Hyperoxia & Arterial & & & & $1470 \pm 208$ & \\
\hline \multicolumn{8}{|l|}{ Glutamic oxaloacetate } \\
\hline \multirow[t]{2}{*}{ transaminase (U/L) } & Normoxia & Arterial & & & & $323 \pm 80$ & \\
\hline & Hyperoxia & Arterial & & & & $298 \pm 66$ & \\
\hline \multirow{3}{*}{$\begin{array}{l}\text { Glutamic-pyruvic } \\
\text { transaminase(U/L) }\end{array}$} & & & & & & & \\
\hline & Normoxia & Arterial & & & & $32 \pm 10$ & \\
\hline & Hyperoxia & Arterial & & & & $36 \pm 13$ & \\
\hline
\end{tabular}

The increases of parameters with respect to baseline values were calculated. Differences between groups were not significant.

* Significant change from baseline values within groups.

there may be other causes for the differences in outcome between the normoxia and hyperoxia groups. Also, this study does not help to determine whether differences in $\mathrm{PaO}_{2}$ before $\mathrm{CPB}$, during cooling, or during rewarming are of equal or indeed any importance. Previous studies of brain tissue $\mathrm{PO}_{2}$ have shown that hyperoxia at normothermia changes the average brain tissue $\mathrm{PO}_{2}$ only minimally. ${ }^{14}$ Furthermore, hyperoxia has been shown to cause cerebral vasoconstriction ${ }^{15}$ that leads to nonhomogeneous oxygen distribution. ${ }^{16}$ Although the relative changes in the NIRS signals support the hypothesis that the improved outcome results from improved oxygen delivery, it is important to remember that the NIRS measurements taken in this study were relative and that there could have been important differences in baseline values. Although such differences cannot be excluded, they are most likely subtle because the redox status of cytochrome is believed to change only under severely hypoxic conditions ${ }^{17}$ and the hemoglobin signal is derived mainly from venous blood in the brain. ${ }^{18}$

Increasing arterial and venous $\mathrm{PO}_{2}$ values during cooling were paralleled by a rising cerebral oxyhemoglobin signal and a decreasing cytochrome $\mathrm{a}, \mathrm{a}_{3}$ signal, which we have seen in previous experimental and clinical studies. ${ }^{13,19}$ Cytochrome a, $\mathrm{a}_{3}$ and oxyhemoglobin concentrations tended to be higher during cooling and during deep hypothermia and circulatory arrest in the hyperoxia group, despite a presumed higher absolute baseline with respect to the normoxia group. Maximal decrease of the cytochrome $\mathrm{a}, \mathrm{a}_{3}$ value during deep hypothermia and circulatory arrest has been shown to correlate with histologically demonstrated brain damage in previous studies from our laboratory. ${ }^{20}$ Furthermore, cytochrome $a_{1} a_{3}$ values have been correlated with adenosine triphosphate levels of the brain during cardiac operations, ${ }^{20}$ suggesting that the energy status of the brain starts to become depleted during cooling before deep hypothermia and circulatory arrest. The paradoxic finding of impaired brain oxygenation despite increasing $\mathrm{PaO}_{2}$ may be explained by hemodilution and an increased affinity of oxygen for hemoglobin with the hypothermia and alkalosis that occur during alpha-stat management. Clinical data and a mathematical model indicate that oxygenation of the brain during deep hypothermia depends on the amount of physically dissolved oxygen. ${ }^{21,22} \mathrm{~A} \mathrm{PaO}_{2}$ within the reference range, such as was used in the normoxia 
group, may be insufficient to meet the oxygen demand of the brain during cooling.

During rewarming $\mathrm{PO}_{2}$ values in the jugular bulb were significantly lower in the normoxia group. Clinical studies have shown that severe desaturation in the jugular bulb during rewarming is associated with postoperative neuropsychologic deficits. ${ }^{23}$

This study confirms a probable reduction in free radical injury with normoxic $\mathrm{CPB}$ management relative to hyperoxic CPB management. However, normoxic perfusion results in greater histologically demonstrated brain injury after a prolonged period of deep hypothermia and circulatory arrest. In view of the findings of phase I of this study that cerebral microemboli are not increased if a membrane oxygenator is used with an arterial filter and despite the limitations of current NIRS technology, the most likely mechanism of increased injury appears to be cerebral neuronal hypoxia. In our clinical practice we therefore currently use pure oxygen for all pediatric CPB.

We thank Mark Cioffi, Pascal Gebeyan, and Christine Rader, from the Department of Cardiac Surgery, Gene Walter, from the Department of Neurology, for technical support during the operations, and Kerry Descoteau for technical assistance with histologic studies. Assistance with data analysis by David Zuraowski, PhD, statistician, Department of Biostatistics, and Frank Perron, $\mathrm{PhD}$, Joslin Diabetes Center, is greatly appreciated. We thank Laura Young for preparation of the manuscript.

\section{REFERENCES}

1. Wyatt JS, Cope M, Delpy DT, van der Zee P, Arridge S, Edwards $\mathrm{AD}$, et al. Measurement of optical path length for cerebral nearinfrared spectroscopy in newborn infants. Dev Neurosci 1990;12:140-4.

2. Esterbauer H, Cheeseman KH. Determination of aldehydic lipid peroxidation products: malonaldehyde and 4-hydroxynonenal. Meth Enzymol 1990;186:407-21.

3. Misko TP, Schilling RJ, Salvemini D, Moore WM, Currie MG. A fluorometric assay for the measurement of nitrite in biological samples. Anal Biochem 1993;214:11-6.

4. Usui A, Kato K, Murase M, Hotta T, Tanaka M, Takeuchi E, et al. Neural tissue proteins in serum and cerebrospinal fluid after cardiac arrest. J Neurol Sci 1994;123:134-9.

5. Horn M, Seger F, Schlote W. Neuron-specific enolase in gerbil brain and serum after transient cerebral ischemia. Stroke 1995; 26:290-7.

6. Yoshikawa T. Atlas of the brains of domestic animals. University Park (PA): Pennsylvania State University Press; 1968.

7. Forbess JM, Ibla JC, Lidov HG, Cioffi MA, Hiramatsu T, Laussen $\mathrm{P}$, et al. University of Wisconsin cerebroplegia in a piglet survival model of circulatory arrest. Ann Thorac Surg 1995; 60(suppl):S494-500.

8. Ihnken K, Morita K, Buckberg GD, Shermann MP, Young HH.
Studies of hypoxemic/reoxygenation injury: without aortic clamping. III. Comparison of the magnitude of damage by hypoxemia/reoxygenation versus ischemia reperfusion. J Thorac Cardiovasc Surg 1995;110:1182-9.

9. Bolling KS, Halldorsson A, Allen BS, Rahman S, Wang T, Kronon M, et al. Prevention of the hypoxic reoxygenation injury with the use of a leukocyte-depleting filter. J Thorac Cardiovasc Surg 1997;113:1081-9.

10. Allen BS, Rahman S, Ilbawi MN, Kronon M, Bolling KS, Halldorsson AO, et al. Detrimental effects of cardiopulmonary bypass in cyanotic infants: preventing the reoxygenation injury. Ann Thorac Surg 1997;64:1381-7.

11. Hiramatsu T, Jonas RA, Miura T, du Plessis A, Tanji M, Forbess $\mathrm{JM}$, et al. Cerebral metabolic recovery from deep hypothermic circulatory arrest after treatment with arginine and nitro-arginine methyl ester. J Thorac Cardiovasc Surg 1996;112:698-707.

12. Tsui SS, Kirshbom PM, Davies MJ, Jacobs MT, Greeley WJ, Kern FH, et al. Nitric oxide production affects cerebral perfusion and metabolism after deep hypothermic circulatory arrest. Ann Thorac Surg 1996;61:1699-707.

13. Shin'oka T, Shum-Tim D, Jonas RA, Lidov HG, Laussen PC, Miura T, et al. Higher hematocrit improves cerebral outcome after deep hypothermic circulatory arrest. J Thorac Cardiovasc Surg 1996;112:1610-20.

14. Leninger-Follert E, Luebbers D, Wrabetz D. Regulation of local $\mathrm{Po}_{2}$ of the brain cortex at differential $\mathrm{O}_{2}$ pressures. Pfluegers Arch 1975;359:81-95.

15. Kety SS, Schmidt CF. The effects of altered tensions of carbon dioxide and oxygen on cerebral blood flow and cerebral oxygen consumption of normal young men. J Clin Invest 1948;27:484-92.

16. Merril CR, Charlton C, Yarnell P, Omaya AK. Effect of arterial oxygen on mammalian brain oxygen tension. Nature 1967; 216:295-7.

17. Edwards AD, Brown GC, Cope M, Wyatt JS, McCormick DC, Roth SC, et al. Quantification of concentration changes in neonatal human cerebral oxidized cytochrome oxidase. J Appl Physiol 1991;71:1907-13.

18. Mchedlishvili G. Cerebral arterial behavior providing constant cerebral blood flow, pressure and volume. In: Mchedlishvili G. Arterial behavior and blood circulation in the brain. New York: Plenum Press; 1986. p. 42-95.

19. Nollert G, Möhnle P, Tassani-Prell P, Reichart B. Determinants of cerebral oxygenation during cardiac surgery. Circulation 1995; 92:(suppl):II327-33.

20. Tsuji M, Naruse H, Volpe J, Holtzman D. Reduction of cytochrome aa3 measured by near-infrared spectroscopy predicts cerebral energy loss in hypoxic piglets. Pediatr Res 1995;37:253-9.

21. Dexter F, Kern FH, Hindman BJ, Greeley WJ. The brain uses mostly dissolved oxygen during profoundly hypothermic cardiopulmonary bypass. Ann Thorac Surg 1997;63:1725-9.

22. Dexter F, Hindman BJ. Theoretical analysis of cerebral venous blood hemoglobin oxygen saturation as an index of cerebral oxygenation during hypothermic cardiopulmonary bypass: a counterproposal to the "luxury perfusion" hypothesis. Anesthesiology 1995;83:405-12.

23. Croughwell ND, Newman MF, Blumenthal JA, White WD, Lewis JB, Frasco PE, et al. Jugular bulb saturation and cognitive dysfunction after cardiopulmonary bypass. Ann Thorac Surg 1994; 58:1702-8. 